
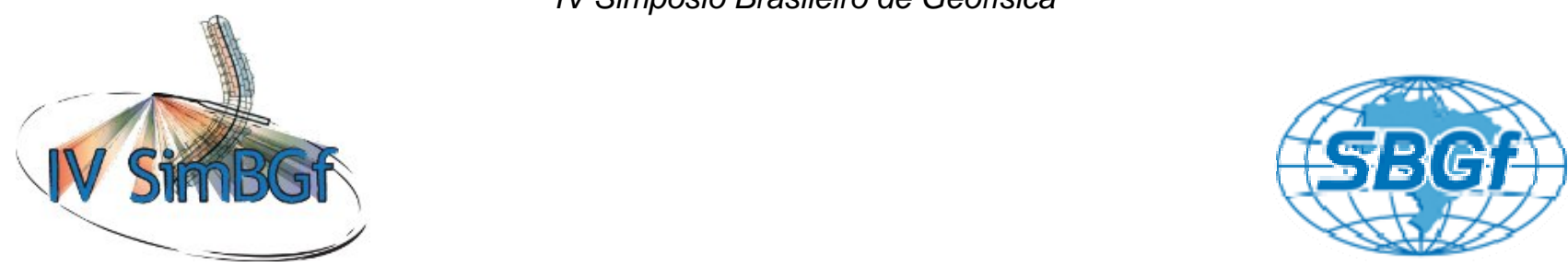

\title{
Gradientes Térmicos Crustais das Bacias Sedimentares na Região Amazônica
}

Elizabeth T. Pimentel ${ }^{1,2}$ e Valiya M. Hamza'; 1- Universidade Federal do Amazonas/UFAM/AM; 2- Observatório Nacional/ON/MCT/RJ.

\section{Copyright 2010, SBGf - Sociedade Brasileira de Geofísica}

Este texto foi preparado para a apresentação no IV Simpósio Brasileiro de Geofísica Brasília, 14 a 17 de novembro de 2010. Seu conteúdo foi revisado pelo Comitê Técnico do IV SimBGf, mas não necessariamente representa a opinião da SBGf ou de seus associados. É proibida a reprodução total ou parcial deste material para propósitos comerciais sem prévia autorização da SBGf.

\section{Resumo}

Results of a regional scale analysis of geothermal gradients are presented for the area covered by sedimentary basins in the Amazon region. The data sets employed in the present work are composed of results of geothermal investigations carried out in 185 localities situated in the sedimentary basins of Acre, Solimões, Amazon, Marajó and Barreirinhas, as well as those obtained over 719 localities in neighboring countries. The mean geothermal gradient values in the study area are found to fall in the range of $21,13 \pm 3,48{ }^{\circ} \mathrm{C} / \mathrm{km}$ to $31,04 \pm$ $2,07^{\circ} \mathrm{C} / \mathrm{km}$. However, geothermal gradient values greater than $40^{\circ} \mathrm{C} / \mathrm{km}$ have also been encountered in the basins of Solimões and Amazon. In the Amazon and Marajó basins the mean gradient values are lower, in the range of 15 to $20^{\circ} \mathrm{C} / \mathrm{km}$. Regional scale mapping have identified the existence of an east - west trending major geothermal belt between the southwestern part of the Acre basin and western part of the Solimões basin. This area is considered as having considerable potential for relatively higher values of thermal maturation levels of hydrocarbons in the sedimentary strata. The high geothermal gradients are also likely to provide favorable conditions for occurrence of geothermal resources located in the upper parts of the basement rocks.

\section{Introdução}

A área Amazônica é de grande interesse para o desenvolvimento da região Norte, devido ao potencial de aproveitamento de recursos minerais e energéticos presentes nas suas camadas subsuperficias. Grande parte das atividades de exploração realizada nesta região se limita á aquisição de dados através de aerolevantamentos e uso de técnicas de sensoriamento remoto. Os resultados alcançados por estes métodos permitiram mapeamentos de recursos nas camadas superficiais. No entanto, determinações das características geológicas e geofísicas das camadas subsuperficiais são possívies somente com a aquisição de dados dessas camadas. Neste contexto, torna-se importante a coleta de dados em furos de exploração mineral, poços de água subterrânea e poços de prospecção de petróleo. Conhecimentos de temperaturas em furos e poços constituem importante ferramenta auxiliar nas avaliações de recursos de energia geotérmica e de hidrocarbonetos. Porém, não foram efetuados até o momento avaliações regionais de gradiente e de fluxo térmico da região Amazônica. O presente trabalho representa uma das primeiras tentativas que visa reavaliação de dados de gradientes geotérmicos das bacias sedimentares da região Amazônica.

\section{Características da Área de Estudo}

A Região Amazônica Brasileira ocupa aproximadamente $5.000 .000 \mathrm{Km}^{2}$ de todo território Nacional. São objetos de estudo deste trabalho bacias sedimentares, as quais ocupam aproximadamente $24 \%$ da área dessa região. A localização das principais bacias sedimentares (Acre, Solimões, Amazonas, Marajó e Barreirinhas) são ilustradas na figura 1.

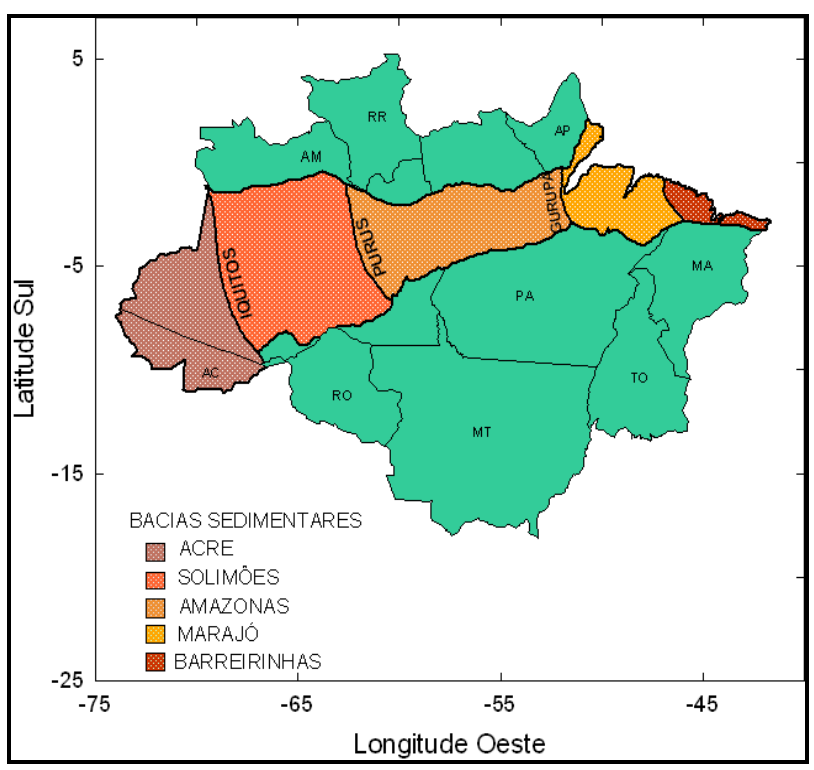

Figura (1) Bacias sedimentares da região Amazônica.

O contexto geológico desta região é marcado pela presença de bacias sedimentares de grande extensão (Acre, Solimões, Amazonas, Marajó e Barreirinhas) formadas sobre embasamentos cratônicos de idade Pré-cambriana. Os núcleos cratônicos afloram tanto na parte norte (escudo Guianense) como na parte Sul (craton Guáporé). A parte oeste é limitada pelas bacias sedimentares Pré-Andinas (Marañon, Ucayali e Madre de Dios em Perú e Llanos em Colômbia). Na parte leste ocorrem as bacias sedimentares da Plataforma continental da Foz de Amazonas.

É prática comum na literatura geológica nacional considerar como limites das bacias intra cratônicas desta região as feições estruturais regionais do embasamento. 
Assim, o arco de Iquitos é considerado como divisor entre as bacias do Acre e Solimões, enquanto o arco do Purus marca a separação entre as bacias Solimões e Amazonas, já o arco de Gurupá divide as bacias Amazonas e Marajó.

\section{Acervos de Dados de Gradientes Geotérmicos}

A compilação efetuada na primeira fase deste trabalho se limitou aos dados de perfilagens térmicas de furos e poços. Foram avaliados no presente trabalho resultados de perfilagens térmicas efetuadas em 960 localidades na região Amazônica. Destes, 241 localidades se encontram em território nacional, dos quais, 185 estão distribuídas entre as bacias sedimentares do Acre, Solimões, Amazonas, Marajó e Barreirinhas, e 56 localidades estão fora dessas bacias. As demais localidades (719 ao todo) se encontram distribuídas nos países vizinhos da Venezuela, Colômbia, Peru e Bolívia. Constam na Tabela (1) os números de locais de medidas geotérmicas avaliados neste trabalho.

Tabela (1) Locais de medidas geotérmicas avaliados neste trabalho.

\begin{tabular}{|c|c|c|}
\hline País & Região / Bacia & $\begin{array}{c}\text { Numero de } \\
\text { Locais }\end{array}$ \\
\hline Brasil & Acre & 12 \\
\hline & Solimões & 16 \\
\hline & Amazonas & 119 \\
\hline & Marajó & 20 \\
\hline & Barreirinhas & 18 \\
\hline \multicolumn{2}{|c|}{ Sub Total Metamórfico } & 56 \\
\hline Venezuela & Cordilheira Norte & 241 \\
\hline Colômbia & Bacia Llanos & 606 \\
\hline Bolívia & Santa Cruz-Tarija & 52 \\
\hline Peru & Bacia Marañon & 21 \\
\hline \multicolumn{2}{|c|}{ Sub Total } & 719 \\
\hline \multicolumn{2}{|c|}{ Total Geral } & 960 \\
\hline
\end{tabular}

\section{Metodologia}

A metodologia empregada na determinação de gradientes térmicos é constituída da utilização de vários métodos, entre eles: a temperatura do fundo de poço de petróleo (BHT); temperatura estável do fundo de poço (CBT); perfilagem térmica convencional (CVL); e geoquímico (GCL). Segundo Hamza e Muñoz (1996) resultados dos primeiros quatro métodos podem ser considerados como de qualidade superior em comparação com àqueles obtidos por métodos geoquímicos.

O método de temperatura de fundo de poço (BHT) é utilizado para determinar gradientes térmicos em poços de petróleo. A principal fonte da incerteza neste método é oriunda principalmente do uso de termômetros de baixa exatidão nas medidas. As medições das temperaturas efetuadas em poços de petróleo precisam ser corrigidas dos efeitos perturbadores das atividades de perfuração. No presente trabalho, os dados BHT com medidas múltiplas de temperaturas, foram corrigidos pelos métodos propostos por Lachenbruch e Brewer (1959) e
Middleton (1980). Nos casos em que havia apenas uma medida de temperatura utilizou-se a correção empírica conhecida como método AAPG (AAPG, 1976).

O método de temperatura estável de fundo do poço (CBT) foi utilizado em casos em que o campo térmico do poço é perturbado pelo fluxo de fluidos no seu interior. Geralmente, a perturbação térmica é praticamente nula na parte próximo ao fundo do poço. Utilizam-se então as temperaturas na parte inferior do poço neste método. No entanto, convém notar que as medições de temperaturas no método CBT são geralmente efetuadas em poços de regimes térmicos estáveis, utilizando termômetros de precisão e, portanto, não necessitam de correções. Por outro lado, o grau de incerteza neste método depende da qualidade de informações utilizada para a determinação exata da temperatura média anual da superfície nos locais de poços.

No método convencional (CVL) os gradientes geotérmicos são determinados para os intervalos de profundidades selecionados, com base em informações de perfil litológico do poço em questão. Os valores foram calculados pelo critério de mínimos quadrados.

Nos casos de poços rasos com indícios de perturbações térmicas foram aplicadas correções para minimizar os efeitos de mudanças climáticas e de topografia local.

\section{Distribuições de temperaturas nas Bacias}

Apresenta-se nos itens seguintes resultados de análises de dados das temperaturas em poços, sendo que o enfoque é a determinação de gradientes térmicos médios das bacias.

Bacia Acre: De acordo com a base de dados as medições das temperaturas foram efetuados em 12 localidades, pelo método BHT. A figura (2) ilustra a distribuição das temperaturas com a profundidade.

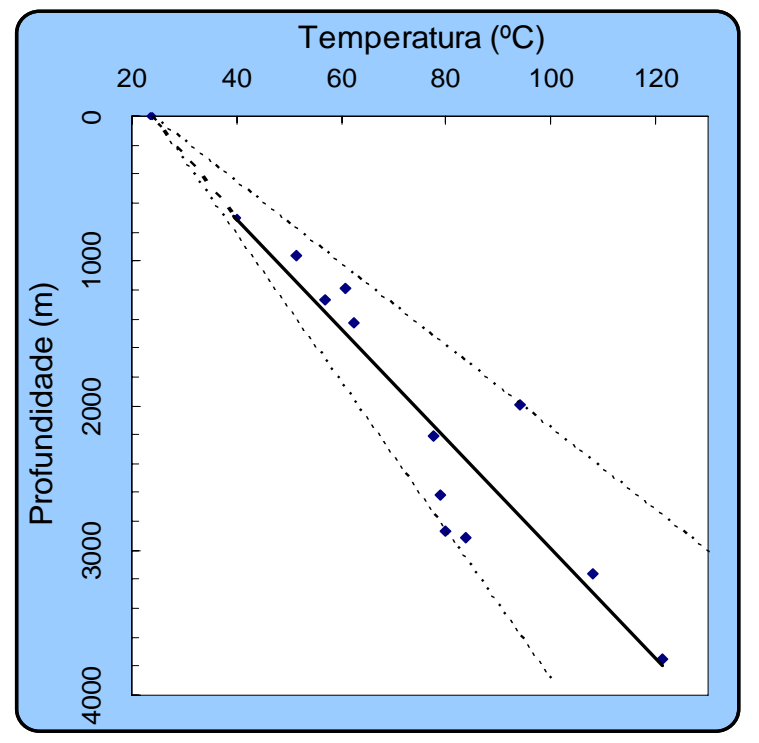

Figura (2) Distribuição das temperaturas com a profundidade na bacia Acre.

Esta bacia é caracterizada por gradiente geotérmico médio de $21,13{ }^{\circ} \mathrm{C} / \mathrm{Km}$, com desvio padrão de 3,48 
${ }^{\circ} \mathrm{C} / \mathrm{Km}$. As temperaturas dos poços individuais apontam gradientes geotérmicos que variam na faixa entre 19,49 a $35,23{ }^{\circ} \mathrm{C} / \mathrm{Km}$, conforme ilustrada na Figura (2). Em profundidades rasas de até $700 \mathrm{~m}, 0$ gradiente geotérmico é $23,57^{\circ} \mathrm{C} / \mathrm{Km}$.

Bacia Solimões: De acordo com a base de dados as medições das temperaturas foram efetuados em 16 localidades, pelo método BHT. A figura (3) ilustra a distribuição das temperaturas com a profundidade.

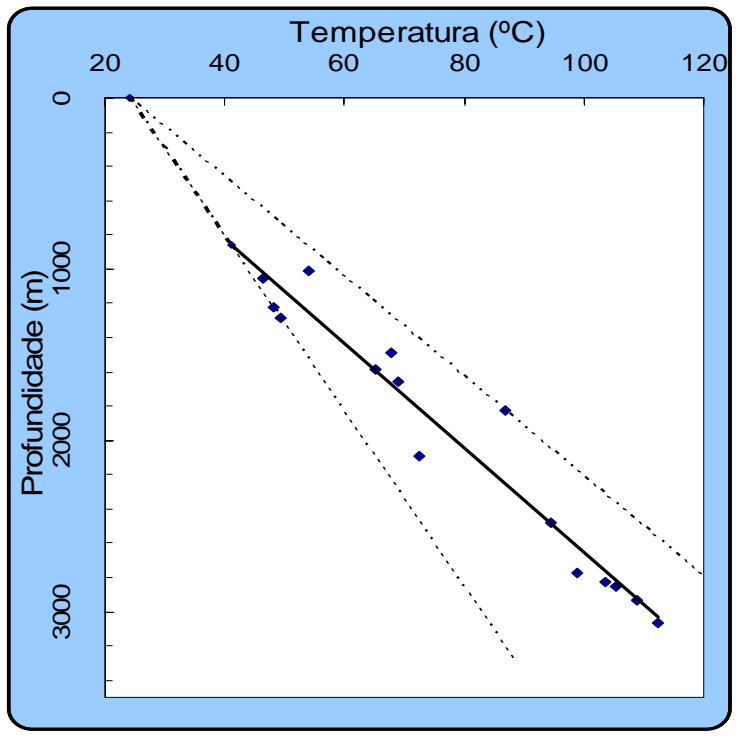

Figura (3) Distribuição das temperaturas com a profundidade na bacia Solimões.

O valor médio dos gradientes geotérmicos característico dessa bacia é de $31,04{ }^{\circ} \mathrm{C} / \mathrm{Km}$, com desvio padrão de $2,07^{\circ} \mathrm{C} / \mathrm{Km}$. A faixa de gradientes encontrada está entre 19,61 a $34,35^{\circ} \mathrm{C} / \mathrm{Km}$. Em profundidades rasas de até 860 $\mathrm{m}$ o valor do gradiente geotérmico é $19,77^{\circ} \mathrm{C} / \mathrm{Km}$, constituindo, desta forma, uma mudança marcante do campo térmico raso em relação ao do profundo.

Bacia Amazonas: De acordo com a base de dados as medições das temperaturas foram efetuados em 103 localidades, pelo método BHT, 15 localidades pelo método CVL e 01 localidade pelo método CBT. A figura (4) ilustra a distribuição das temperaturas com a profundidade.

A faixa da variação dos valores dos gradientes geotérmicos se encontra no intervalo de 17,51 a 35,43 ${ }^{\circ} \mathrm{C} / \mathrm{Km}$. O valor do gradiente geotérmico médio é de $25,68^{\circ} \mathrm{C} / \mathrm{Km}$, com desvio padrão de $1,24{ }^{\circ} \mathrm{C} / \mathrm{Km}$. Em profundidades rasas de até $1000 \mathrm{~m}$ o valor do gradiente geotérmico é $17,50{ }^{\circ} \mathrm{C} / \mathrm{Km}$, significativamente inferior ao valor médio desta bacia.

Bacia Marajó: De acordo com a base de dados as medições das temperaturas foram efetuados em 15 localidades, pelo método BHT e 05 localidades pelo método CVL. A figura (5) ilustra a distribuição das temperaturas com a profundidade.
A variação dos valores dos gradientes geotérmicos da bacia Marajó é de 16,59 a $34,23{ }^{\circ} \mathrm{C} / \mathrm{Km}$, sendo caracterizada pelo valor do gradiente geotérmico médio de $23,24^{\circ} \mathrm{C} / \mathrm{Km}$, com desvio padrão de $1,77^{\circ} \mathrm{C} / \mathrm{Km}$. Em profundidades rasas de até $650 \mathrm{~m}$, o gradiente geotérmico é de $22,31^{\circ} \mathrm{C} / \mathrm{Km}$, esse valor não é significativamente diferente do valor médio desta bacia.

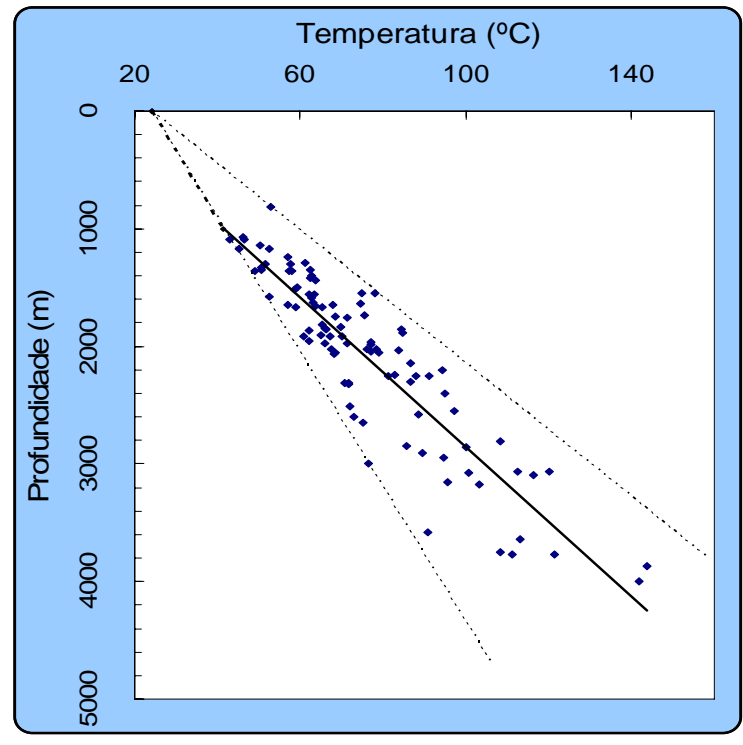

Figura (4) Distribuição das temperaturas com a profundidade na bacia Amazonas.

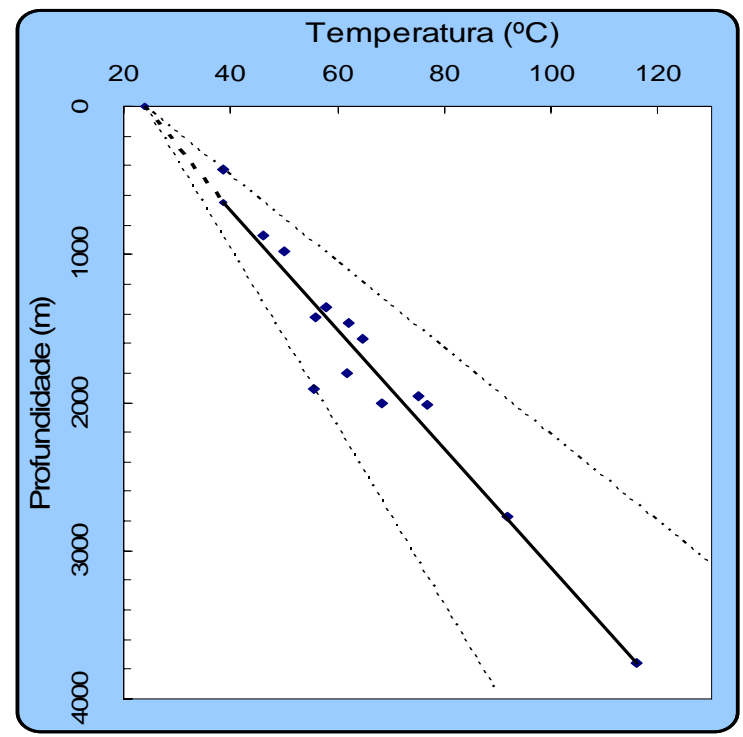

Figura (5) Distribuição das temperaturas com a profundidade na bacia Marajó.

Bacia Barreirinhas: De acordo com a base de dados as medições das temperaturas foram efetuados em 18 localidades, pelo método BHT. A figura (6) ilustra a distribuição das temperaturas com a profundidade.

A caracterização da bacia Barreirinhas se dá por variações nos valores dos gradientes geotérmicos entre 
17,25 a $29,45{ }^{\circ} \mathrm{C} / \mathrm{Km}$. O valor médio do gradiente geotérmico é de $28,23{ }^{\circ} \mathrm{C} / \mathrm{Km}$, com desvio padrão de $3,07{ }^{\circ} \mathrm{C} / \mathrm{Km}$. Para profundidades de até $1140 \mathrm{~m}$, o gradiente geotérmico é de $18,77^{\circ} \mathrm{C} / \mathrm{Km}$, que é significativamente inferior ao valor médio desta bacia.

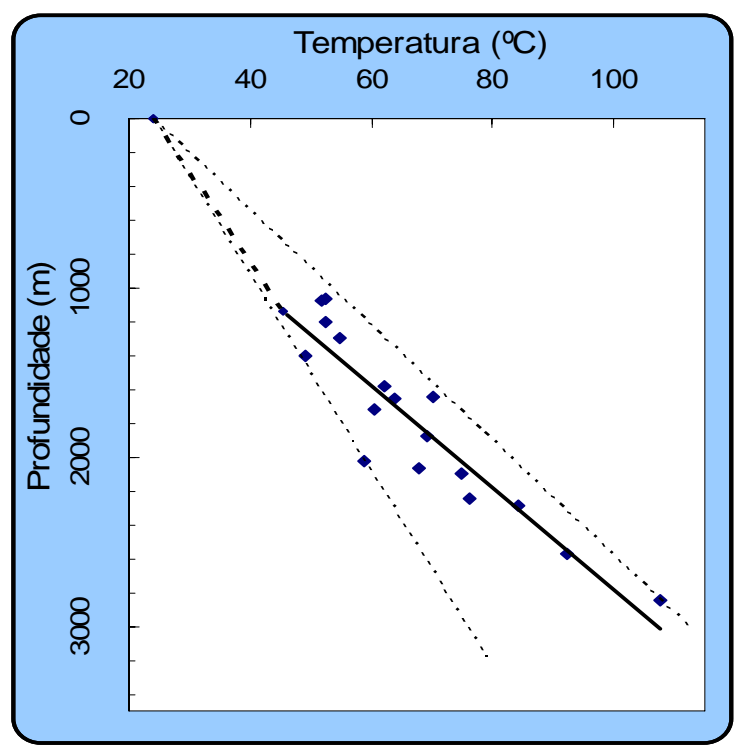

Figura (6) Distribuição das temperaturas com a profundidade na bacia Barreirinhas.

Consta na Tabela (2) um sumário de valores de gradientes térmicos calculados para essas bacias.

\begin{tabular}{|c|c|c|}
\hline \multirow{2}{*}{ Bacia } & $\begin{array}{c}\text { Intervalo de } \\
\text { Profundidades }\end{array}$ & $\begin{array}{c}\text { Gradiente } \\
\text { Geotérmico } \\
{ }^{\circ} \mathrm{C} / \mathrm{Km}\end{array}$ \\
\hline \multirow{2}{*}{ Acre } & $0-700$ & 23,57 \\
\cline { 2 - 3 } Solimões & $700-3747$ & $21,13 \pm 3,48$ \\
\cline { 2 - 3 } & $0-860$ & 19,77 \\
\hline \multirow{2}{*}{ Amazonas } & $0-1000$ & 17,50 \\
\cline { 2 - 3 } & $1000-4026$ & $25,68 \pm 1,24$ \\
\hline \multirow{2}{*}{ Marajó } & $0-650$ & 22,31 \\
\cline { 2 - 3 } & $650-3762$ & $23,24 \pm 1,77$ \\
\hline \multirow{2}{*}{ Barreirinhas } & $0-1140$ & 18,95 \\
\cline { 2 - 3 } & $1140-3109$ & $28,23 \pm 3,07$ \\
\hline
\end{tabular}

\section{Mapas Geotermais}

Os mapas geotermais foram elaborados com intuito de ilustrar as variações regionais nos gradientes térmicos. Os procedimentos adotados incluem a construção de uma malha regular de dados com base em interpolações de valores observados. O intervalo de gridagem adotada varia de acordo com a densidade de dados disponíveis. Apresenta-se nos itens a seguir os resultados obtidos.

Bacia Acre: O mapa apresentada na Figura (7) indica valores de gradientes térmicos na faixa de 14 a $22^{\circ} \mathrm{C} / \mathrm{Km}$ na parte oeste. $\mathrm{Na}$ parte leste a faixa de valores encontrados é de 22 a $32^{\circ} \mathrm{C} / \mathrm{Km}$. Os valores relativamente baixos de gradientes na parte oeste são determinados em parte pelos dados da bacia de Marañon no Peru.

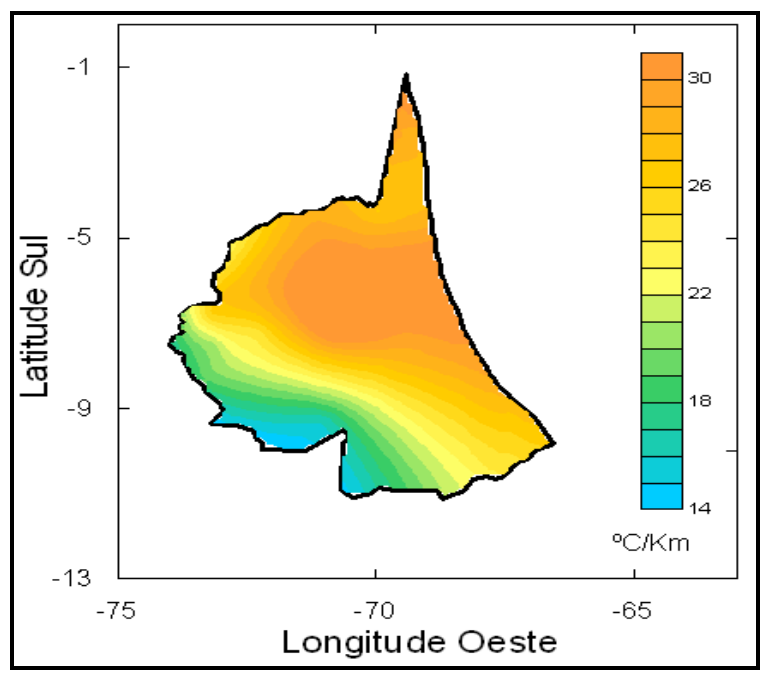

Figura (7) Mapa dos gradientes geotérmicos da bacia Acre.

Bacia Solimões: O mapa apresentado na Figura (8) indica valores de gradientes térmicos na faixa de 22 a 32 ${ }^{\circ} \mathrm{C} / \mathrm{Km}$ em quase toda região desta bacia. A única exceção é a região central de arco de Purus onde há indícios de valores menores na faixa de 18 a $22^{\circ} \mathrm{C} / \mathrm{Km}$. Os valores relativamente elevados de gradientes ocorrem na parte sudoeste da bacia, o que é continuação de gradientes térmicos elevados da parte leste da bacia do Acre.

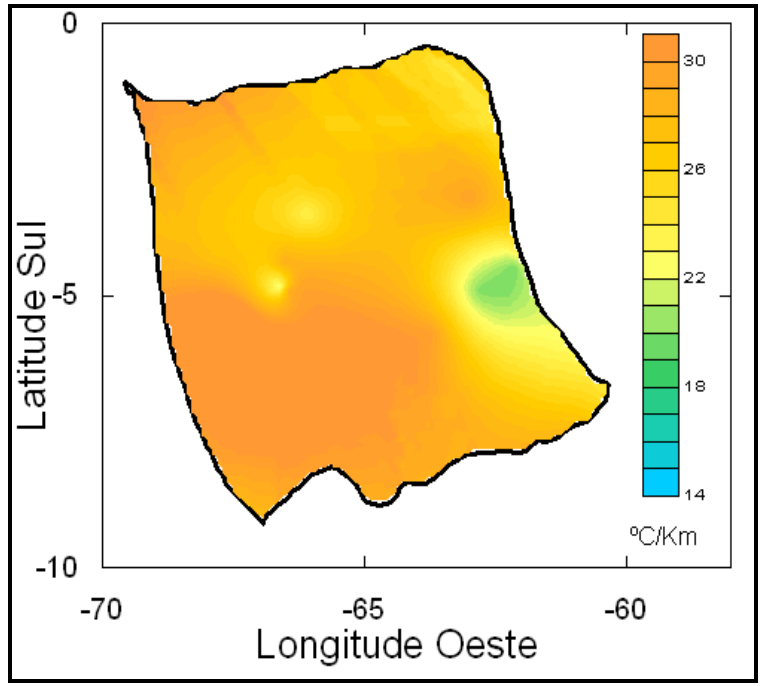

Figura (8) Mapa dos gradientes geotérmicos da bacia Solimões.

Bacia Amazonas: O mapa apresentado na Figura (9) indica um padrão complexo de gradientes térmicos nesta bacia, com valores na faixa de 18 a $32^{\circ} \mathrm{C} / \mathrm{Km}$. Observase que a bacia é constituida de um mosaico de blocos 
com variações significativas nos gradientes térmicos. Há indícios de que os arcos de Purus e Gurupá são caracterizados por valores relativamente elevados de gradientes térmicos.

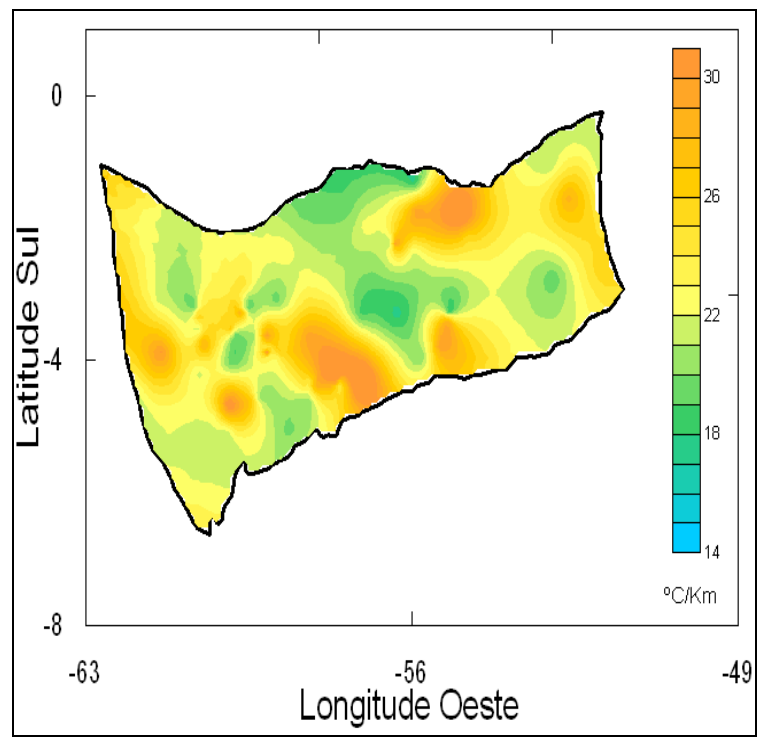

Figura (9) Mapa dos gradientes geotérmicos da bacia Amazonas.

Bacia Marajó: A baixa densidade de dados dificulta a interpretação das variações regionais de gradientes térmicos nesta bacia. De modo geral, o mapa apresentado na Figura (10), indica um padrão de gradientes térmicos semelhante ao encontrado na bacia do Amazonas, com valores na faixa de 18 a $32^{\circ} \mathrm{C} / \mathrm{Km}$.

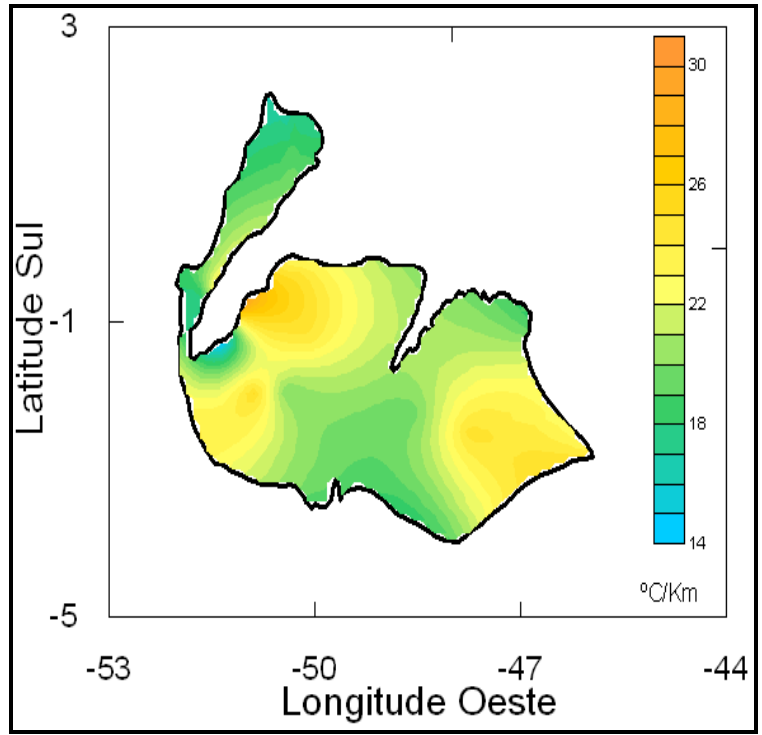

Figura (10) Mapa dos gradientes geotérmicos da bacia Marajó.

Bacia Barreirinhas: A baixa densidade de dados também dificulta a interpretação das variações regionais de gradientes térmicos nesta bacia. De modo geral, o mapa apresentado na Figura (11), indica um padrão de gradientes térmicos semelhante ao encontrado na bacia de Marajó, com valores na faixa de 18 a $32{ }^{\circ} \mathrm{C} / \mathrm{Km}$.

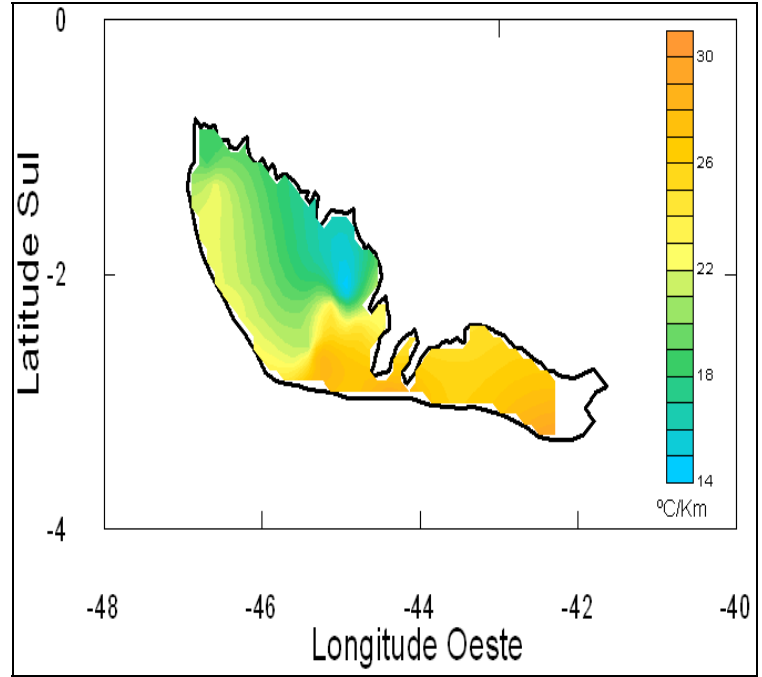

Figura (11) Mapa dos gradientes geotérmicos da bacia Barreirinhas.

\section{Conclusões}

A reavaliação de dados geotérmicos das bacias sedimentares da Região Amazônica revela que o regime térmico desta região é caracterizado por gradientes geotérmicos médios na faixa de $21,13 \pm 3,48{ }^{\circ} \mathrm{C} / \mathrm{km}$ a $31,04 \pm 2,07{ }^{\circ} \mathrm{C} / \mathrm{km}$. Os menores valores foram encontrados nas bacias de Marajó e Amazonas e os maiores valores nas bacias de Acre e Solimões. As distribuições verticais são caracterizadas pela presença de zonas de baixos valores de gradientes térmicos em profundidades menores que 1000 metros em quase todas as bacias. Ocorrências de valores relativamente elevados de gradientes térmicos foram identificadas na porção leste da bacia do Acre e a porção sudoeste da bacia do Solimões. Nessas regiões as condições térmicas se encontram favoráveis á maturação de hidrocarbonetos. Ainda, há indícios da existência de recursos geotermais nas áreas de maiores valores dos gradientes geotérmicos.

\section{Agradecimentos}

O primeiro autor deste trabalho é recepiente da Bolsa de estudos concedido pela Fundação de Amparo à Pesquisa do Estado do Amazonas - FAPEAM.

Agradecemos Dr. Iris Escobar Pereira pelo apoio da Coordenadoria de Geofísica do Observatório Nacional.

\section{Referências}

AAPG, 1976. American Association of Petroleum Geologists, Basic data file from AAPG Geothermal Survey of North America, Univ. of Oklahoma, Norman. 
Araujo, R. L. C. Contribuição da Geotermia Rasa aos Estudos Ambientais, Manaus: ed. EDUA, 1999. 88p.

Carvalho, H. S., Vacquiers, V., 1977. Method for determining terrestrial heat flow in oil fields, Geophysics, v. 42 , no. 3 , p. 584-593.

Carvalho, H. S., 1981. Métodos para determinação de fluxo geotérmico com aplicação as bacias sedimentares petrolfferas do Recôncavo baiano (Brasil) e Sumatra (Indonesia).Unpublished Ph.D. thesis, Univ. Federal da Bahia, Salvador, Brazil.

Carvalho, H. S., Simres Lobo, P. F., Prazeres Campos, J. N. and Zembruscki, S. G.,1987. Estudo do fluxo de calor e movimentação de fluidos na bacia do Médio Amazonas. Rev. Bras. Geof. 5,231-243.

Gomes, A.J.L., Hamza, V.M., 2003. Avaliação de Recursos Geotermais do Estado do Rio de Janeiro, $8^{\circ}$.International Congress of the Brazilian Geophysical Society, Rio de Janeiro.

Hamza, V.M., Muñoz, M., 1996. Heat Flow Map of South America, Geothermics, Vol. 25, nº 6, pg 599-646. Great Britain.

Hamza, V.M. and Silva Dias, F. J. S., 2003. Functional Representation of regional heat flow in South America: Implications for the occurrence of low-temperature geothermal resources, Geothermal Resources Council Transactions, V. 27, pp. 615-618.

Lachenbruch, A.H. and M.C. Brewer, 1959. Dissipation of the temperature effect of drilling a well in Arctic Alaska, U.S. Geological Survey Bulletin 1083-C, 109 pp.

Meister, E.M., 1973. Gradientes geotérmicos nas bacias sedimentares Brasileiras, Boletim Técnico Petrobrás, 16 (4), 221-232.

Middleton, M.F., 1979. A model for bottom-hole temperature stabilization: Geophysics, v. 44, no. 8, p. 1458-1462.

Oliveira, F.N.M., Araújo, R.L.C., Carvalho, J.S. e Silva, C.L., 2006. Inferência de mudanças climáticas na região de Manaus (AM) usando dados geotermais e meteorológicos. Rev. Bras. Geof., vol.24, $\mathrm{n}^{\circ} .2,169-187$.

Ribeiro, F., Hamza, V. M., 1986, Modelling thermal disturbances induced by drilling activity: Advances in theory and practice, Rev. Bras. Geofísica, 4, 91-106.

Ribeiro, F.B., 1988, Estudo sobre o problema da determinação de temperaturas de equilíbrio em poços afetados pela atividade de perfuração, Tese de Doutorado, IAG / USP, São Paulo.

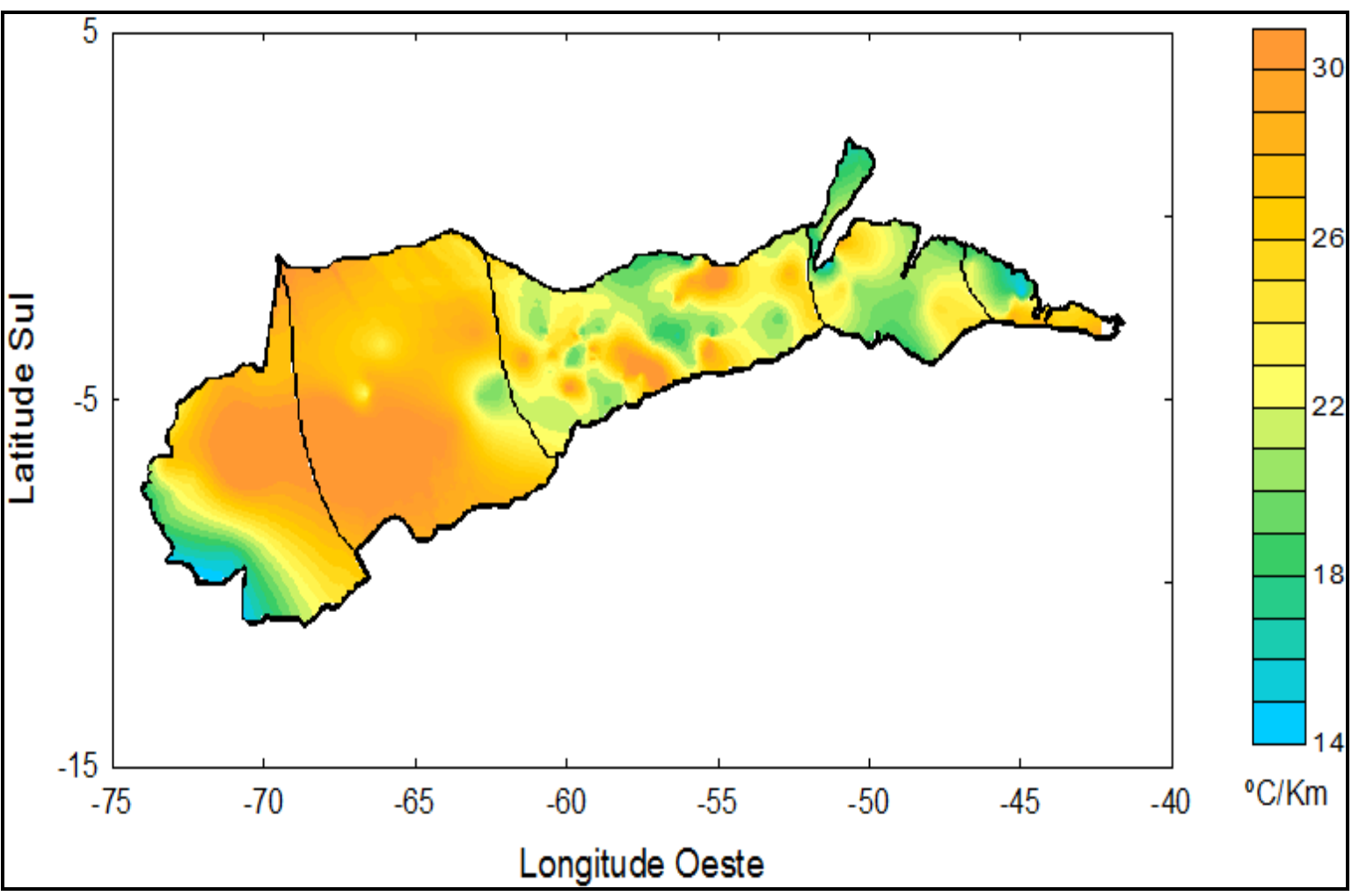

Figura (12) Mapa dos gradientes geotérmicos das bacias sedimentares da região Amazônica. 